\title{
Diagnostic utility of DREAM gene mRNA levels in thyroid tumours
}

Fernando A. Batista', Marjory A. Marcello', Mariana B. Martins', Karina C. Peres', Ulieme O. Cardoso', Aline C. D. N. Silva', Natassia E. Bufalo', Fernando A. Soares², Márcio J. da Silva³', Lígia V. Assumpção', Laura S. Ward'

\begin{abstract}
Objective: The transcriptional repressor DREAM is involved in thyroid-specific gene expression, thyroid enlargement and nodular development, but its clinical utility is still uncertain. In this study we aimed to investigate whether DREAM mRNA levels differ in different thyroid tumors and how this possible difference would allow the use of DREAM gene expression as molecular marker for diagnostic and/or prognosis purpose. Materials and methods: We quantified DREAM gene mRNA levels and investigated its mutational status, relating its expression and genetic changes to diagnostic and prognostic features of 200 thyroid tumors, being 101 malignant [99 papillary thyroid carcinomas (PTC) and 2 anaplastic thyroid carcinomas] and 99 benign thyroid lesions [49 goiter and 50 follicular adenomas (FA)]. Results: Levels of mRNA of DREAM gene were higher in benign $(0.7909 \pm 0.6274 \mathrm{AU})$ than in malignant $(0.3373 \pm 0.6274 \mathrm{AU})$ thyroid lesions $(\mathrm{p}<0.0001)$. DREAM gene expression was able to identify malignancy with $66.7 \%$ sensitivity, $85.4 \%$ specificity, $84.2 \%$ positive predictive value (PPV), 68.7\% negative predictive value (NPV), and 75.3\% accuracy. DREAM mRNA levels were also useful distinguishing the follicular lesions FA and FVPTC with $70.2 \%$ sensitivity, $73.5 \%$ specificity, $78.5 \%$ PPV, 64.1\% NPV, and 71.6\% accuracy. However, DREAM gene expression was neither associated with clinical features of tumor aggressiveness, nor with recurrence or survival. Six different genetic changes in non-coding regions of DREAM gene were also found, not related to $D R E A M$ gene expression or tumor features. Conclusion: We suggest that DREAM gene expression may help diagnose thyroid nodules, identifying malignancy and characterizing follicular-patterned thyroid lesions; however, it is not useful as a prognostic marker. Arch Endocrinol Metab. 2018;62(2):205-11
\end{abstract}

Keywords

Calsenilin; diagnostic; follicular thyroid lesion; KChIP-3; thyroid nodules
${ }^{1}$ Laboratório de Genética Molecular do Câncer (Gemoca), Faculdade de Ciências Médicas (FCM), Universidade Estadual de Campinas (Unicamp), Campinas, SP, Brasil 2 Departamento de Patologia, Hospital A.C. Camargo -

Fundação Antonio Prudente, São Paulo, SP, Brasil

${ }^{3}$ Centro de Biologia Molecular e Engenharia Genética (CBMEG), Universidade Estadual de Campinas (Unicamp), Campinas, SP, Brasil

\section{Correspondence to:}

Laura S. Ward

Laboratório de Genética Molecular do Câncer (Gemoca), Faculdade de Ciências Médicas (FCM),

Universidade Estadual de Campinas (Unicamp)

Rua Tessalia Vieira de Camargo, 126, Cidade Universitária Zeferino Vaz 13083-887 - Campinas, SP, Brasil ward@fcm.unicamp.br

Received on May/15/2017 Accepted on Nov/8/2017

DOI: $10.20945 / 2359-3997000000028$

\section{INTRODUCTION}

A $\mathrm{n}$ important increase in the incidence of thyroid cancer has been observed worldwide, mainly because of a better access to high resolution image exams, such as ultrasound, and frequent fine-needle aspiration (FNA) biopsies of small nodules (1-4). Despite the advantages of cytological analysis using FNA, this method has limitations, not being able to diagnose reliably a substantial part of thyroid nodules. Hence, many patients are submitted to thyroid resection for a definitive diagnosis, and postsurgical exams reveal no need for surgery in approximately $75 \%$ of these cases (4-7). A series of diagnostic markers has been proposed and some molecular platforms are particularly helpful in thyroid cancer diagnosis, but their implementation in clinical routine is still difficult (8). The determination of prognosis in thyroid cancer patient is problematic as well. Although most patients have satisfactory outcome, recurrences are relatively frequent and up to $10-15 \%$ of cases may present an aggressive behavior characterized by metastases during follow-up, eventually leading to death (9). Reliable markers able to predict poor outcome during followup are utmost needed in clinical practice $(2,4)$.

The DREAM gene (downstream regulatory element antagonist modulator) has been mapped to chromosome $2 \mathrm{qll} .1$ and has nine exons. The product of this gene, an homonymous protein, also identified as KchIP-3 (K channel-interacting protein 3 ) or calsenilin, belongs to the KchIP family, composed by four proteins (KChIPl-4) (10). DREAM has the ability to directly bind to specific DNA sites, the downstream regulatory elements (DRE), acting as a transcriptional repressor (11). Under basal conditions, DREAM binds to DRE, resulting in repression of transcription of target genes. Activation of DREAM, which can happen by increasing 
nuclear calcium or by direct phosphorylation by PKA, results in the disruption of the DREAM-DRE binding, which enables gene transcription $(10,12,13)$. DREAM may also connect to Kv4 potassium channels in the membrane as an accessory subunit, regulating their opening through stimulation by calcium (14). $D R E A M$ expression is found in the central nervous system, organs of the immune system, tests and thyroid (10). Although previous studies have suggested that DREAM has an important role as a mediator in several thyroid signaling pathways, and it is also involved in the regulation of follicular cellular functions (15-17), a possible clinical utility of DREAM as a biomarker for diagnosis or prognosis of thyroid lesions has not been explored. For these reasons, we quantified DREAM mRNA levels, and investigated the occurrence of its genetic alterations both in benign and malignant thyroid nodules, comparing the presence of these alterations and/or expression levels to diagnostic and prognostic features of these tumors.

\section{MATERIALS AND METHODS}

\section{Patients}

We investigated a total of 200 patients whose tissue samples were maintained in the tissue bank of the AC Camargo Cancer Hospital, São Paulo, Brazil. Fresh thyroid tissue samples were obtained from 101 patients diagnosed with thyroid carcinoma (TC): 99 papillary thyroid carcinomas (PTCs), including 63 classic papillary thyroid carcinomas (CPTC), 36 follicular variants of papillary thyroid carcinomas (FVPTC); and two anaplastic thyroid carcinomas (ATC). In addition, there were 49 nodular goiters and 50 follicular adenomas (FA). Four normal tissues from the contralateral lobe of four goiter cases were obtained as well. The diagnosis of TC was based on standard clinical criteria described in our previous article (18).

All patients were treated according to a standard protocol $(19,20)$ and followed for 12-87 months with a median follow-up of 3.16 years ( $38 \pm 17$ months).

This study was approved by the Research Ethics Committees of the institutions involved (Process \# $821,805)$. All procedures performed in this study were in accordance with the ethical standards of the institutional and national research committee and the 1964 Helsinki declaration and its later amendments or comparable ethical standards.

\section{Quantitative real-time PCR (qPCR)}

We were able to extract RNA from all 204 samples. Total RNA was extracted from pulverized frozen thyroid tissues using Trizol reagent (Invitrogen Life Technologies Inc., Carlsbad, CA, USA), according to the manufacturer instructions. The samples were digested with Amplification Grade DNAse I (Life Technologies, Rockville, MD, USA) and reversetranscribed using SuperScript III reverse-transcriptase (Invitrogen Life Technologies Inc.). The assays were carried out with the use of commercially available TaqMan gene expression assays (Applied Biosystems) for DREAM (Hs01106289_ml) relative to the internal reference gene GAPDH (Hs02758991_gl). Reactions were prepared with TaqMan gene expression master mix (Applied Biosystems), according to the manufacturer protocol. Analysis was performed with a 7500 RT-PCR system (Applied Biosystems, Foster City, CA, USA), using a four-stage program: $50^{\circ} \mathrm{C}$ for $2 \mathrm{~min}, 95^{\circ} \mathrm{C}$ for $10 \mathrm{~min}, 40$ cycles of $95^{\circ} \mathrm{C}$ for $15 \mathrm{~s}$, and $60^{\circ} \mathrm{C}$ for $1 \mathrm{~min}$. Each sample was assayed in triplicate. Threshold cycle (Ct) was obtained using the sequence detection software (Applied Biosystems SDS vl.3 Software). We used $\triangle \Delta \mathrm{CT}$, in which the amount of target (DREAM) normalized to an endogenous reference and relative to calibrator is given by $2^{-\Delta \Delta \mathrm{T}}$. The expression levels were given in arbitrary units (AU).

\section{Sequencing the coding regions of DREAM gene}

The coding regions of DREAM gene were amplified by PCR using the following primers (all 5'-3', forward and reverse respectively): AGGGGTGGAGCGATAGAAG and CAAAGGAAAGTGGAACAAGAG for exon $\quad$; $\quad$ CCCATCTTACACCATAGCCA and GGGAAGGGTGTGAATGAATG for exon 2; GGTAGTCATGCAAAGAGAGTTC and TTTCCCACAACACATAAGCC for exon 3; CAAGGGGGTGGAGAGAGG and CCCAGGGTGACTCACAAGAT for exons 4 and 5; AATGGATGCCGTCAGTCTCT and CCGAGAACACTTGCTGAGCT for exon 6; CTTCTCTCTCCAGCTCGTC and GAGTAGGGAGGCTCAGAGG for exon 7; CCAGAGTAGTCACAGGGGCA and AGACAAGAGGGCAAGTGGAG for exon 8; CTCCCTGCACCAATAAGAC and CTGGCAGGATGGAGGTTTCT for exon 9. PCR was 
performed in $20 \mu \mathrm{L}$ volume of a mixture containing $100 \mathrm{ng}$ of DNA, $5 \mathrm{mM}$ of each primer, $2 \mu \mathrm{L}$ of $10 \mathrm{X}$ PCR Buffer, $150 \mu \mathrm{M}$ of each dinucleotide triphosphate, $1 \mathrm{U}$ Taq DNA polymerase, $1.5 \mathrm{mM} \mathrm{MgCl}$ and deionized water up to $20 \mu \mathrm{L}$. Amplifications were carried out for 35 cycles of $94^{\circ} \mathrm{C}$ for 30 seconds, $55^{\circ} \mathrm{C}$ for 50 seconds and $72^{\circ} \mathrm{C}$ for 1 minute, with an initial denaturation step of $94^{\circ} \mathrm{C}$ for 5 minutes and a final extension step of $72^{\circ} \mathrm{C}$ for 10 minutes, using a MJ PTC-200 PCR system. Purification was performed using ExoSAPIT (USB Products, Cleveland, $\mathrm{OH}$ ). The samples were submitted to automated sequencing using the SANGER method. For this reaction, we used for each sample: $13.5 \mu \mathrm{L}$ of water, $4 \mu \mathrm{L}$ of save money $5 \mathrm{x}$ buffer, $1 \mu \mathrm{L}$ of each primer, $0.5 \mu \mathrm{L}$ of BigDye buffer and $1 \mu \mathrm{L}$ of the purified sample. The following cycles were used in the sequencing reaction: initial cycle of 1 min and $30 \mathrm{~s}$ at $96^{\circ} \mathrm{C}$, followed by 25 cycles of $96^{\circ} \mathrm{C}$ for $12 \mathrm{~s}, 50^{\circ} \mathrm{C}$ for $6 \mathrm{~s}$ and $60^{\circ} \mathrm{C}$ for $4 \mathrm{~min}$. Sequencing reactions were performed using Eppendorf PCR BD3700 system and separated on an ABI Prism 3700 DNA Analyzer (Applied Biosystems, Foster, CA, USA). All sequences were analyzed using CLC DNA Workbench ${ }^{\circledR}$ (Katrinebjerg, Denmark) software and compared with the DREAM genomic sequence (ENSG00000115041).

\section{Statistical analysis}

Statistical analysis was carried out using the SAS System for Windows (Statistical Analysis System, version 9.1.3, Service Pack 3 Institute Inc., 2002-2003, Cary, NC, USA). For the analysis of correlation of DREAM gene expression and clinical and pathological features of aggressiveness, patients were classified according to age of diagnosis, gender, tumor size, presence of extrathyroidal invasion, presence of capsule, multifocality, presence of metastasis at diagnosis and TNM. For the comparison with patients outcome, the population as classified according to response to treatment, as recommended by the latest ATA guidelines (4). The Mann-Whitney tests were used to compare continuous or arranged measures between two groups; Kruskal-Wallis test was used to compare three or more groups. The accuracy of gene expression studies to predict malignancy and/or differentiate follicular lesions was evaluated using receiver operating curve (ROC) analysis, based on predicted probabilities from logistic regression models. Recurrence-free survival was calculated using Kaplan-Meier survival curves with log rank comparison. For this analysis, the
TC patients were divided in two groups, low expression of DREAM $(\leq 0.2 \mathrm{AU})$ and normal/hyperexpression of DREAM (>0.2AU). All tests were conducted at the significance level $p=0.05$.

\section{RESULTS}

As expected, thyroid cancer patients were predominantly females $(75.3 \%)$ aged $14-70$ years old $(41.1 \pm 14.3$ years $)$ at the time of diagnosis. The 101 patients of the thyroid cancer group did not differ from the 99 individuals with benign thyroid diseases concerning gender $(67$ females and 22 males vs. 78 females and 16 males, respectively) or age at diagnosis $(45.6 \pm 16.3$ years old $v s .48 .5 \pm 14.8$ years old, respectively). Multifocality was observed in $37 \%$ of the patients and $26 \%$ presented invasion of the capsule. Stage I $(66 \%)$ and stage II $(29 \%)$ were more frequent than stage III $(3 \%)$ and stage IV $(2 \%)$ cases. Metastasis at the time of diagnosis was observed in $45 \%$ of the patients.

\section{DREAM mRNA levels}

DREAM mRNA level comparison between benign and malignant lesions is summarized in Table 1 . As presented in Figure 1, the levels were significantly higher in benign $(0.7909 \pm 0.6274 \mathrm{AU})$ than in malignant nodules $(0.3373 \pm 0.6274 \mathrm{AU} ; \mathrm{p}<0.0001)$. Among the different histological types of tumors, we found higher mRNA levels of DREAM gene in goiter, followed by FA, FVPTC and CPTC respectively, as represented in Figure 2. Furthermore, DREAM gene expression was able to distinguish goiter and FA, goiter and FVPTC, goiter and CPTC, FA and CPTC, and the follicular-patterned lesions, FA and FVPTC, as shown in Table 1.

Table 1. Comparisons of different histopathological types according to their DREAM mRNA levels

\begin{tabular}{lcc}
\hline Analyzed groups & DREAM mRNA levels $\Delta \Delta$ Ct (qPCR) & p value \\
\hline Malignant vs. & & \\
Benign & $0.3373 \pm 0.6274$ vs. $0.7909 \pm 0.6274$ & $<0.0001$ \\
Goiter vs. FA & $0.7816 \pm 0.6512$ vs. $0.8001 \pm 0.6160$ & 0.6725 \\
Goiter vs. FVPTC & $0.7816 \pm 0.6512$ vs. $0.3449 \pm 0.2221$ & 0.0069 \\
Goiter vs. CPTC & $0.7816 \pm 0.6512$ vs. $0.3281 \pm 0.2261$ & 0.0002 \\
FA vs. FVPTC & $0.8001 \pm 0.6160$ vs. $0.3449 \pm 0.2221$ & 0.0002 \\
FA vs. CPTC & $0.8001 \pm 0.6160$ vs. $0.3281 \pm 0.2261$ & $<0.0001$ \\
FVPTC vs. CPTC & $0.3449 \pm 0.2221$ vs. $0.3281 \pm 0.2261$ & 0.6378 \\
\hline
\end{tabular}




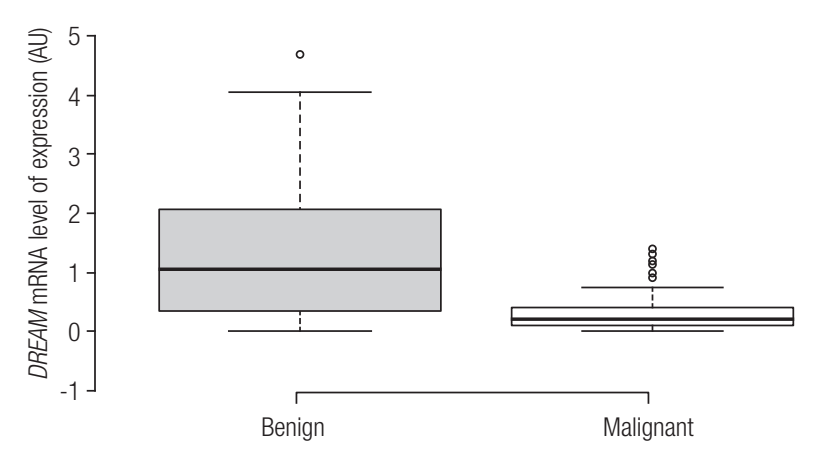

Figure 1. DREAM mRNA expression by quantitative $P C R$ in benign and malignant thyroid lesions $(P<0.0001)$.

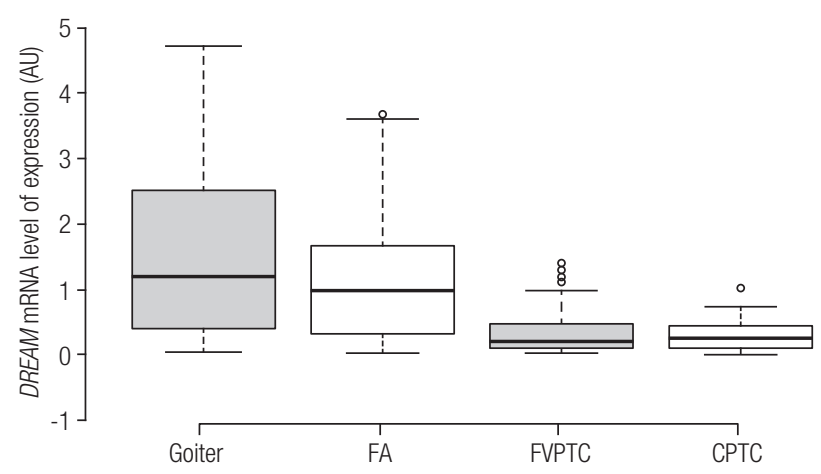

Figure 2. DREAM mRNA expression by quantitative PCR in goiter, follicular adenoma (FA), follicular variant papillary thyroid carcinoma (FVPTC) and classic papillary thyroid carcinoma (CPTC).

Aiming to investigate the diagnostic utility of DREAM gene expression, we further performed ROC analysis based on predicted probabilities from logistic regression models. Using a cutoff of $0.528 \mathrm{AU}$, $D R E A M$ was able to predict malignancy in thyroid nodules with $66.7 \%$ sensitivity, $85.4 \%$ specificity, $84.2 \%$ positive predictive value (PPV), $68.7 \%$ negative predictive value (NPV), and $75.3 \%$ accuracy. DREAM mRNA levels were also useful in distinguishing the follicular lesions FA and FVPTC with 70.2\% sensitivity, 73.5\% specificity, 78.5\% PPV, 64.1\% NPV, and 71.6\% accuracy, using a cutoff value of $0.405 \mathrm{AU}$.

Although DREAM gene mRNA levels were different among thyroid lesions, there was no association with any clinical or pathological parameter of tumor aggressiveness and there was no association with patient outcomes (Table 2, Figure 3).

\section{DREAM mutational analysis}

We were able to perform mutational analysis of all 9 exons of DREAM gene in all 200 samples. There were no genetic changes in the coding regions. However, we found 6 single base substitutions in noncoding regions near the amplified coding regions (Table 3 ). No association was found regarding clinical or pathological features, and we were unable to demonstrate any variation of mRNA levels in association with the observed sequence substitutions.

\section{DISCUSSION}

In the present study we report higher mRNA levels of DREAM gene in benign thyroid tumours when

Table 2. Comparison of DREAM mRNA levels to clinical and pathological features of aggressiveness and outcome of 101 thyroid carcinomas

\begin{tabular}{|c|c|c|}
\hline Variable & DREAM expression & $p$ value \\
\hline \multicolumn{3}{|l|}{ Age of diagnosis } \\
\hline$<45$ & $0.44 \pm 0.51$ & 0.76 \\
\hline$>45$ & $0.46 \pm 0.66$ & \\
\hline \multicolumn{3}{|l|}{ Gender } \\
\hline Male & $0.34 \pm 0.30$ & 0.9 \\
\hline Female & $0.48 \pm 0.67$ & \\
\hline \multicolumn{3}{|l|}{ Tumour size } \\
\hline$<2 \mathrm{~cm}$ & $0.20 \pm 0.31$ & \\
\hline $2-4 \mathrm{~cm}$ & $0.33 \pm 0.33$ & 0.23 \\
\hline$>4 \mathrm{~cm}$ & $0.39 \pm 0.45$ & \\
\hline \multicolumn{3}{|l|}{ Extrathyroidal invasion } \\
\hline Present & $0.46 \pm 0.65$ & 0.83 \\
\hline Absent & $0.40 \pm 0.45$ & \\
\hline \multicolumn{3}{|l|}{ Presence of capsule } \\
\hline Present & $0.48 \pm 0.60$ & 0.27 \\
\hline Absent & $0.44 \pm 0.61$ & \\
\hline \multicolumn{3}{|l|}{ Multifocality } \\
\hline Present & $0.35 \pm 0.26$ & 0.24 \\
\hline Absent & $0.49 \pm 0.72$ & \\
\hline \multicolumn{3}{|l|}{ Metastasis at diagnosis } \\
\hline Present & $0.48 \pm 0.62$ & 0.32 \\
\hline Absent & $0.38 \pm 0.48$ & \\
\hline \multicolumn{3}{|l|}{ TNM } \\
\hline । & $0.94 \pm 0.42$ & 0.43 \\
\hline$\|$ & $0.71 \pm 0.38$ & \\
\hline III & $0.67 \pm 0.57$ & \\
\hline IV & $0.41 \pm 0.00$ & \\
\hline \multicolumn{3}{|l|}{ Outcome* } \\
\hline Excellent response & $0.49 \pm 0.10$ & 0.61 \\
\hline Incomplete response & $0.82 \pm 0.40$ & \\
\hline
\end{tabular}

* Classification according to recommendation of American Thyroid Association 2015 guidelines (4). Incomplete responses were grouped together due to insufficient number of structural incomplete response cases for statistical analysis. Indeterminate response cases were excluded from the analysis. 
compared to malignant thyroid lesions. By comparing different histologic types of tumours, we also described higher DREAM gene expression not only presents potential identifying malignancy but also distinguishing the follicular-patterned lesions AF and CPVF. We also described the presence of intronic genetic changes of $D R E A M$ gene in thyroid nodules patients. Although this is, to our knowledge, the first study of the DREAM gene comprehending malignant and benign thyroid nodules, previous studies have already demonstrated the importance of DREAM for the normal function of the thyroid gland, which may justify the possible loss of

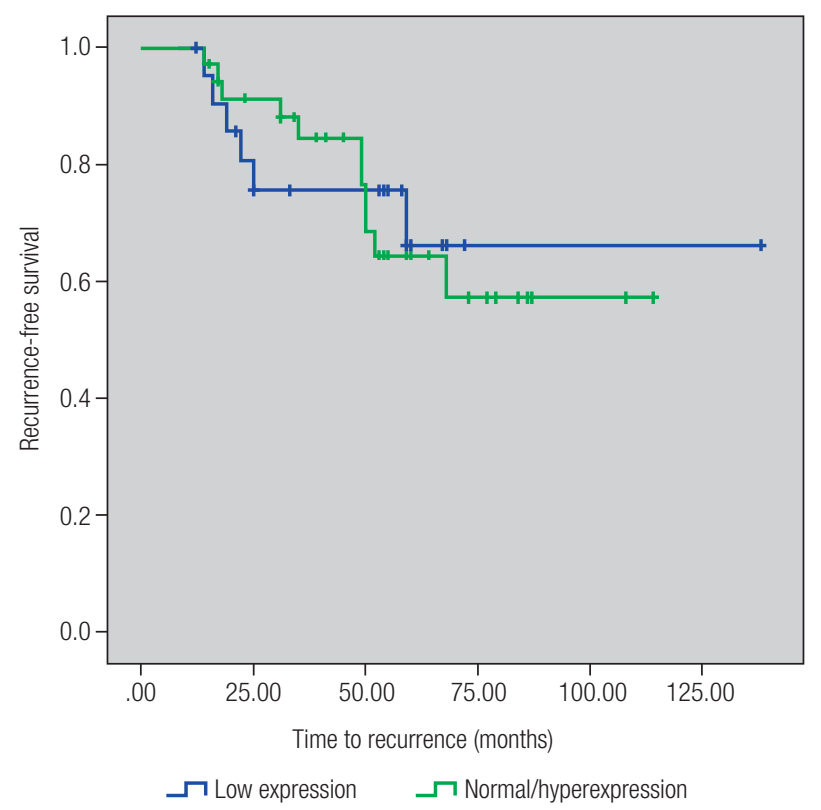

Figure 3. Kaplan-Meier curve comparing patterns of recurrence-free survival between patients according to DREAM gene expression.

Table 3. Genetic changes in DREAM gene found in this study

\begin{tabular}{|c|c|c|c|}
\hline ID (rs) & Localization & Nucleotide & Allelic frequency \\
\hline \multirow{2}{*}{-} & \multirow{2}{*}{$\begin{array}{l}\text { Promoter } \\
\text { region }\end{array}$} & \multirow{2}{*}{ IVS-95T>A } & $A=0.9975(399 / 400)$ \\
\hline & & & $T=0.0025(01 / 400)$ \\
\hline \multirow{2}{*}{ rs2248415 } & \multirow{2}{*}{ Intron1 } & \multirow{2}{*}{ IVS1+41C>G } & $C=0.2500(100 / 400)$ \\
\hline & & & $G=0.7500(300 / 400)$ \\
\hline \multirow{2}{*}{-} & \multirow{2}{*}{ Intron1 } & \multirow{2}{*}{ IVS2-131C>T } & $C=0.0050(02 / 400)$ \\
\hline & & & $T=0.9950(398 / 400)$ \\
\hline \multirow{2}{*}{ rs117109173 } & \multirow{2}{*}{ Intron3 } & \multirow{2}{*}{ IVS3+10G>C } & $C=0.940(376 / 400)$ \\
\hline & & & $G=0.0600(24 / 400)$ \\
\hline \multirow{2}{*}{-} & \multirow{2}{*}{ Intron3 } & \multirow{2}{*}{ IVS3+17T >C } & $T=(0.0025(01 / 400)$ \\
\hline & & & $C=0.9975(399 / 400)$ \\
\hline \multirow[t]{2}{*}{ rs58372613 } & \multirow[t]{2}{*}{ Intron7 } & \multirow[t]{2}{*}{ IVS8-118C>T } & $C=0.4300(112 / 400)$ \\
\hline & & & $\mathrm{T}=0.5700(288 / 400)$ \\
\hline
\end{tabular}

expression during the dedifferentiation process of the gland. Rivas and cols., demonstrated that, in thyroid follicular cells, DREAM interacts directly with the thyroid transcription factor-1 (TTF-1) by modulating its transcriptional activity, and acts in the regulation of gene expression of thyroglobulin and the other two main thyroid-specific transcription factors PAX8 and FOXE1 (15), both involved in thyroid differentiation $(21,22)$. DREAM can still act as intracellular effector of TSH receptor (TSHR), activating the signaling cascade by cAMP (adenosine 3',5'-cyclicmonophosphate) independently of stimulation by TSH, which is suggested by Rivas and cols., as a possible mechanism of development of multinodular goiter by describing overexpression of DREAM in 10 of 16 human samples (16). Similarly, Shinzato and cols. described overexpression of DREAM gene in $53.3 \%$ of a cohort composed of 60 multinodular goiter patients (23). Our data is compatible with these findings, being goiter the lesion which presented higher levels of DREAM mRNA compared to any other histological type of the analyzed thyroid samples. The same study also reports mutational analysis of DREAM. The SNPs rs 2248415 and rs 117109173 , found in a 75 and $6 \%$ of our patients respectively were also described by them in 91.6 and $8.3 \%$ of their patients respectively. In our analysis, the intronic polymorphisms did not correlate in DREAM mRNA levels in different thyroid lesions and, similarly to previously published, do not seem to be associated with differential DREAM expression (23).

The expression pattern of DREAM in different thyroid lesions rise the hypothesis of a possible involvement of this transcription repressor in the tumorigenesis and dedifferentiation of the thyroid gland. Although the exact mechanism by which DREAM could possibly play a role in this process remains unknown, there are multiple paths to be explored. The lower expression of DREAM in malignant lesions may play a role in thyroid carcinogenesis given to the proapoptotic activity, thanks to the direct interaction with the presenilin 2(PS2) protein, which culminates in the activation of the caspase cascade (24). The above mentioned transcriptional modulation activity of DREAM on PAX8 and FOXE1 gene expression (15) could also explain the lower mRNA levels in malignant thyroid tissue, since both genes are involved in thyroid differentiation. Our previous findings about mRNA levels of thyroid specific transcription factors in thyroid tumours corroborate this hypothesis: both PAX8 
and FOXEI follow a similar expression pattern than $D R E A M$, being highly expressed in benignant lesions compared to malignant lesions (18). A third possibility would be the involvement of DREAM as repressor of the immune response. Savignac and cols. have previously demonstrated that transient knockdown of DREAM induced basal expression of interleukin-2 and interferon gamma in wild-type splenocytes (25). Recent publications from our group have demonstrated the important role which the immune system plays in thyroid cancer behaviour (26-29). Further investigation could lead to the identification of DREAM as one of the many molecules which take part in this association.

The differential expression of the DREAM gene described by us rises the possibility of use of this gene as a molecular marker. Although DREAM mRNA levels failed to identify aggressiveness and predict prognosis, there is potential for the use as a diagnostic marker. A comparison with some of the currently available panels of molecular markers can be seen on Table 4. DREAM specificity (85\%), was better than Afirma (52\%), Rosetta microRNA classifier $(72 \%)$ and ThyGenX ${ }^{\circledR} /$ ThyraMIR $^{\mathrm{TM}}$ (85\%). Despite its low NPV (69\%), DREAM presented the second best PPV (84\%), higher than other four panels (ThyroSeq v2, 77\%; Afirma, 47\%; Rosetta microRNA classifier, 59\%; and ThyGenX ${ }^{\circledR} /$ ThyraMIR $\left.^{\mathrm{TM}}, 74 \%\right)$. Perhaps the most interesting comparison is the one between DREAM expression and Afirma, given the fact that this gene expression classifier (GEC) test which possesses high NPV and sensitivity (93 and $92 \%$ respectively), has relatively low specificity and PPV (52 and $47 \%$ respectively). As a result, more than a half of the patients tested positive by the Afirma GEC may still have a benign disease on surgical pathology. On the contrary, DREAM presented much higher PPV and specificity values ( 84 and $85 \%$

Table 4. Comparison of sensitivity, specificity, NPV and PPV values of DREAM mRNA levels in thyroid tumours with some currently available panels of thyroid cancer molecular markers

\begin{tabular}{lcccc}
\hline & Sensitivity & Specificity & NPV & PPV \\
\hline DREAM mRNA levels & $67 \%$ & $85 \%$ & $69 \%$ & $84 \%$ \\
Seven-gene panel (30) & $63 \%$ & $99 \%$ & $94 \%$ & $88 \%$ \\
ThyroSeq v2 $^{\circledR}(31)$ & $91 \%$ & $92 \%$ & $97 \%$ & $77 \%$ \\
Afirma (32) & $92 \%$ & $52 \%$ & $93 \%$ & $47 \%$ \\
Rosetta microRNA & & & & \\
classifierTM (33) & $85 \%$ & $72 \%$ & $91 \%$ & $59 \%$ \\
ThyGenX ${ }^{\circledR}$ and & & & & \\
ThyraMIRTM (34) & $89 \%$ & $85 \%$ & $94 \%$ & $74 \%$ \\
\hline
\end{tabular}

respectively) but much lower NPV and sensitivity value (69 and 67\% respectively). We suggest that DREAM gene expression may not be useful as a single marker, but could be part of a panel of markers of malignancy, like the GEC test. Also, it may help identify follicular lesions, one of the major challenges in clinical practice.

In conclusion, our investigation demonstrated a possible diagnostic utility of DREAM gene mRNA levels in the identification of thyroid nodule malignancy and differentiation of follicular-patterned thyroid lesions. In addition, we demonstrated the presence of intronic changes of DREAM gene in patients with thyroid nodules, although these changes were not related to clinical features.

Acknowledgements: the authors would like to thank financial support from the Foundation for Research of the State of São Paulo (Fapesp) for the financial support (grant \# 2013/18683-7) and our group from the Laboratory of Cancer Molecular Genetics (Gemoca) of the School of Medical Sciences, Unicamp. The authors declare that they have no conflict of interest.

Disclosure: no potential conflict of interest relevant to this article was reported.

\section{REFERENCES}

1. NikiforovYE, Nikiforova MN. Molecular genetics and diagnosis of thyroid cancer. Nat Rev Endocrinol. 2011;7(10):569-80.

2. Pitoia F, Ward L, Wohllk N, Friguglietti C, Tomimori E, Gauna A, et al. Recommendations of the Latin American Thyroid Society on diagnosis and management of differentiated thyroid cancer. Arq Bras Endocrinol Metabol. 2009;53(7):884-7.

3. Ahn HS, Kim HJ, Welch HG. Korea's thyroid-cancer "epidemic"-screening and overdiagnosis. N Engl J Med. 2014;371(19):1765-7.

4. Haugen BR, Alexander EK, Bible KC, Doherty GM, Mandel SJ, Nikiforov YE, et al. 2015 American Thyroid Association Management Guidelines for Adult Patients with Thyroid Nodules and Differentiated Thyroid Cancer: The American Thyroid Association Guidelines Task Force on Thyroid Nodules and Differentiated Thyroid Cancer. Thyroid. 2016;26(1):1-133.

5. Melillo RM, Santoro M. Molecular biomarkers in thyroid FNA samples. J Clin Endocrinol Metab. 2012;97(12):4370-3.

6. Wang CC, Friedman L, Kennedy GC, Wang H, Kebebew E, Steward $\mathrm{DL}$, et al. A large multicenter correlation study of thyroid nodule cytopathology and histopathology. Thyroid. 2011;21(3):243-51.

7. Bryson PC, Shores CG, Hart C, Thorne L, Patel MR, Richey L, et al. Immunohistochemical distinction of follicular thyroid adenomas and follicular carcinomas. Arch Otolaryngol Head Neck Surg. 2008;134(6):581-6.

8. Ward LS, Kloos RT. Molecular markers in the diagnosis of thyroid nodules. Arq Bras Endocrinol Metabol. 2013;57(2):89-97.

9. Jemal A, Siegel R, Xu J, Ward E. Cancer statistics, 2010. CA Cancer J Clin. 2010;60(5):277-300.

10. Carrión AM, Link WA, Ledo F, Mellström B, Naranjo JR. DREAM is a Ca2+-regulated transcriptional repressor. Nature. 1999;398(6722):80-4.

11. Carrión AM, Mellström B, Naranjo JR. Protein kinase A-dependent derepression of the human prodynorphin gene via differential 
binding to an intragenic silencer element. Mol Cell Biol. 1998;18(12):6921-9.

12. Ledo F, Carrión AM, Link WA, Mellström B, Naranjo JR. DREAMalphaCREM interaction via leucine-charged domains derepresses downstream regulatory element-dependent transcription. Mol Cell Biol. 2000;20(24):9120-6.

13. Sanz C, Mellstrom B, Link WA, Naranjo JR, Fernandez-Luna $\mathrm{JL}$. Interleukin 3-dependent activation of DREAM is involved in transcriptional silencing of the apoptotic Hrk gene in hematopoietic progenitor cells. EMBO J. 2001;20(9):2286-92.

14. An WF, Bowlby MR, Betty M, Cao J, Ling HP, Mendoza G, et al. Modulation of A-type potassium channels by a family of calcium sensors. Nature. 2000;403(6769):553-6.

15. Rivas M, Mellström B, Naranjo JR, Santisteban P. Transcriptional repressor DREAM interacts with thyroid transcription factor-1 and regulates thyroglobulin gene expression. J Biol Chem. 2004;279(32):33114-22.

16. Rivas M, Mellström B, Torres B, Cali G, Ferrara AM, Terracciano D, et al. The DREAM protein is associated with thyroid enlargement and nodular development. Mol Endocrinol. 2009;23(6):862-70.

17. D'Andrea B, Di Palma T, Mascia A, Motti ML, Viglietto G, Nitsch L, et al. The transcriptional repressor DREAM is involved in thyroid gene expression. Exp Cell Res. 2005;305(1):166-78.

18. Batista FA, Ward LS, Marcello MA, Martins MB, Peres KC, Torricelli $C$, et al. Gene expression of thyroid-specific transcription factors may help diagnose thyroid lesions but are not determinants of tumor progression. J Endocrinol Invest. 2016;39(4):423-9.

19. Ward LS, Maciel LM. Thyroid consensuses: guidelines for clinical practice. Arq Bras Endocrinol Metabol. 2013;57(3):161-2.

20. American Thyroid Association (ATA) Guidelines Taskforce on Thyroid Nodules and Differentiated Thyroid Cancer, Cooper DS, Doherty GM, Haugen BR, Kloos RT, Lee SL, Mandel SJ, et al. Revised American Thyroid Association management guidelines for patients with thyroid nodules and differentiated thyroid cancer. Thyroid. 2009;19(11):1167-214.

21. Civitareale D, Saiardi A, Falasca P. Purification and characterization of thyroid transcription factor 2. Biochem J. 1994;304(Pt 3):981-5.

22. Plachov D, Chowdhury K, Walther C, Simon D, Guenet JL, Gruss P. Pax8, a murine paired box gene expressed in the developing excretory system and thyroid gland. Development. 1990;110(2):643-51.

23. Shinzato A, Lerario AM, Lin CJ, Danilovic DS, Marui S, Trarbach EB. Evaluation of Downstream Regulatory Element Antagonistic Modulator Gene in Human Multinodular Goiter. Med Sci Monit Basic Res. 2015;21:179-82.
24. Lilliehook C, Chan S, Choi EK, Zaidi NF, Wasco W, Mattson MP, et al. Calsenilin enhances apoptosis by altering endoplasmic reticulum calcium signaling. Mol Cell Neurosci. 2002;19(4):552-9.

25. Savignac M, Pintado B, Gutierrez-Adan A, Palczewska M, Mellström B, Naranjo JR. Transcriptional repressor DREAM regulates T-lymphocyte proliferation and cytokine gene expression. EMBO J. 2005;24(20):3555-64.

26. Cunha LL, Nonogaki S, Soares FA, Vassallo J, Ward LS. Immune Escape Mechanism is Impaired in the Microenvironment ofThyroid Lymph Node Metastasis. Endocr Pathol. 2017;28(4):369-372.

27. Cunha LL, Morari EC, Nonogaki S, Marcello MA, Soares FA, Vassallo $\mathrm{J}$, et al. Interleukin 10 expression is related to aggressiveness and poor prognosis of patients with thyroid cancer. Cancer Immunol Immunother. 2017;66(2):141-8.

28. Cunha LL, Marcello MA, Nonogaki S, Morari EC, Soares FA, Vassallo J, et al. CD8+ tumour-infiltrating lymphocytes and COX2 expression may predict relapse in differentiated thyroid cancer. Clin Endocrinol (Oxf). 2015;83(2):246-53.

29. Cunha LL, Marcello MA, Ward LS. The role of the inflammatory microenvironment in thyroid carcinogenesis. Endocr Relat Cancer. 2014;21(3):R85-R103.

30. Nikiforov YE, Ohori NP, Hodak SP, Carty SE, LeBeau SO, Ferris $\mathrm{RL}$, et al. Impact of mutational testing on the diagnosis and management of patients with cytologically indeterminate thyroid nodules: a prospective analysis of 1056 FNA samples. J Clin Endocrinol Metab. 2011;96(11):3390-7.

31. Nikiforov YE, Carty SE, Chiosea SI, Coyne C, Duvvuri U, Ferris $\mathrm{RL}$, et al. Impact of the Multi-Gene ThyroSeq Next-Generation Sequencing Assay on Cancer Diagnosis in Thyroid Nodules with Atypia of Undetermined Significance/Follicular Lesion of Undetermined Significance Cytology. Thyroid. 2015;25(11):1217-23.

32. Alexander EK, Kennedy GC, Baloch ZW, Cibas ES, Chudova D, Diggans J, et al., Preoperative diagnosis of benign thyroid nodules with indeterminate cytology. N Engl J Med. 2012;367(8):705-15.

33. Bar D, Meiri E, et al. A First-of-its-Kind, microRNA-based Diagnostic Assay for Accurate Thyroid Nodule Classification. 15th International Thyroid Congress (ITC) and 85th Annual Meeting of the American Thyroid Association (ATA), Orlando, Florida, 2015.

34. Labourier E, Beaudenon A, Wylie D, GiordanoTJ. Multi-categorical testing for miRNA, mRNA and DNA on fine needle aspiration improves the preoperative diagnosis of thyroid nodules with indeterminate cytology. 97th Meeting and Expo of the Endocrine Society; 2015. p. SAT-344. 